Research Article

\title{
The Implementation of the Lesson Study Strategy in Teaching Mathematics: Teachers' Perspectives
}

\author{
Naem M. Alamri (10) \\ King Saud University, College of Education, Curriculum and Instruction Deptartment, Riyadh, Saudi Arabia \\ Correspondence should be addressed to Naem M. Alamri; nalamry@ksu.edu.sa
}

Received 2 January 2020; Revised 21 June 2020; Accepted 27 July 2020; Published 20 August 2020

Academic Editor: Haoran Xie

Copyright (C) 2020 Naem M. Alamri. This is an open access article distributed under the Creative Commons Attribution License, which permits unrestricted use, distribution, and reproduction in any medium, provided the original work is properly cited.

\begin{abstract}
Lesson study is a form of classroom inquiry that can facilitate teachers' continuing professional development. This study aims to explore primary school mathematics teachers' perspectives about the implementation of the lesson study strategy in teaching mathematics. The sample of this study included 149 primary school mathematics teachers in Riyadh, Saudi Arabia, who were selected by using the purposive sampling. A quantitative questionnaire was sent to the teachers by e-mail or mobile. 149 mathematics teachers responded to the questionnaire; among them, fifteen teachers participated in a qualitative interview. The results indicated that most of the sample members carry out lesson study activities. The percentages of the teachers in the study sample who practice the activities and procedures of the lesson study ranged between $61.7 \%$ and $89.9 \%$. The results also indicated that there is a high impact on the professional development of mathematics teachers as a result of their participation in the lesson study strategy as it helps enhance their mathematical and pedagogical knowledge, improve their knowledge of students' learning process, and influence their views about the lesson study approach.
\end{abstract}

\section{Introduction}

The calls for improvements in professional development have been strengthened over the past few years, with the emergence of many proposals and directions to lead this endeavour. The approaches and models of professional development varied in their ideas, tools, means, and methods of implementation according to the nature and philosophy of teaching and learning. The traditional professional development that takes place through attending short programs, such as a one-day workshop, is usually designed to convey a specific set of ideas or introduce some strategies or materials with little or no follow-up to facilitate implementation in the classroom, a pattern that is widespread in training teachers in many educational systems, and it is considered an ineffective development in bringing about change in classroom procedures, as these workshops and short programs generally tend to be disjointed and do not provide a great opportunity for teachers to collaborate with each other and reflect on practices with their colleagues. This made teaching remain a largely isolated career, and one of the teachers rarely had an opportunity to communicate well with another [1].

Current approaches to teacher preparation and professional development, in which teachers act as researchers, have been the main focus of many educational studies [2-4]. One of these emerging approaches for professional development is the lesson study (LS) approach, which originated in Japan, since the second half of the twentieth century, as a form of teachers' continuing professional development, enabling them to learn from their teaching experiences [5-9]. Professional development through LS allows teachers to examine their practices in the classroom setting.

The LS approach involves collaboration among a team of teachers to plan a lesson where a research lesson is taught by a teacher, while others observe his teaching with an emphasis on student learning. Participants seek to verify the extent to which the lesson has achieved the required goals and to identify difficulties that arise based on this analysis, and the lesson is reviewed and retaught in another class [10]. Previous research studies [11-13] have identified the following five activities that are conducted during the LS: (1) 
identifying goals for student learning; (2) developing a "research lesson" to meet these goals; (3) enacting the lesson with students, with one teacher teaching the lesson and the others collecting data on student learning; (4) reflecting on the lesson plan enactment to improve the lesson; and (5) revising and reteaching the lesson.

It can thus be said that the LS approach is a carefully planned teaching strategy to improve students' learning by allowing them to understand different ideas and the nature of their conceptions [14]. Most important features of effective continuous professional development for teachers are incorporated in LS $[15,16]$. It has been asserted that inquirybased LS depends on teachers' collaborative investigations, which may improve teachers' self-efficacy in teaching science and mathematics and enable them to enhance their pedagogical content knowledge (PCK) of science and mathematics $[5,6,17]$.

LS as a continuing professional development approach may systematically deepen teachers' PCK and understanding and develop their teaching skills and their ability to observe and understand student learning $[2,16,18,19]$. It may serve as a process for producing deep and grounded reflection about complex teaching activities that can be shared and discussed with other members of the profession [15]. The LS approach covers the following aspects [20]: (a) students' cooperation with others in their learning, (b) contextual teaching and learning, (c) life skills, (d) hands-on activities, (e) interactive process-oriented curriculum and syllabi development, and (f) teachers and students' autonomy. Figure 1 shows the stages of the lesson study and the most prominent procedures involved in each stage:

Several studies confirmed the effectiveness of the lesson study in developing teachers' specialized and pedagogical knowledge, developing their skills in teaching mathematical topics, and making them more aware of students' needs [21-23]. This approach also helped them overcome difficulties facing students and improve student learning [1, 24]. The results of previous studies also proved the establishment of positive cooperative relationships between teachers, increasing self-confidence, and developing their reflective practices $[10,25]$.

1.1. Context of the Study. The lesson study (LS) approach is still new in Saudi Arabia; it has been applied only for a few years ago [26], as part of a collaboration between the Ministry of Education of Saudi Arabia and the Ministry of Education of Japan within the framework of the Kingdom's Vision 2030. The Vision 2030 plan aims to improve education and its processes and outputs and to develop professional learning communities capable of identifying their problems and resolving them, as well as producing new knowledge and employing it in schools (National Center for Educational Professional Development) [27]. However, it is not yet clear whether this approach is compatible with the educational system in Saudi Arabia. Where lesson study originated in the Japanese learning environment differs from the education environment in Saudi Arabia. The differences between the two education systems lay on the teacher training and development culture. Thus, the success of the lesson study in achieving an effective professional development for teachers in Japan for many years does not guarantee the same outcomes for the Saudi education environment. Therefore, there is an urgent need to conduct many studies on lesson study in contexts other than Japanese learning, such as the Saudi Arabian system, to explore the extent of the success of its application, the nature of the practices and procedures that take place in it, highlighting and enhancing the positive aspects, discovering the difficulties or obstacles facing its application, and working to overcome them.

This study also aims to determine whether LS as a professional development approach is compatible with the educational system in Saudi Arabia.

\subsection{Research Questions}

(1) What activities do mathematics teachers conduct in LS?

(2) What is the nature of the topics used by mathematics teachers to implement LS in the classroom?

(3) What are the mathematics content domains through which mathematics teachers carry out LS?

(4) How frequently do mathematics teachers practice LS activities in their teaching?

(5) What is the perceived impact of the LS strategy on primary school mathematics teachers' professional development?

\section{Methods}

This is a mixed-method study with sequential explanatory design that examined the understanding and classroom practices of mathematics teachers after their participation in the groups of the LS strategy. Quantitative and qualitative approaches (questionnaire and interview) were used to achieve the following objectives of the present study: (1) to explore activities and procedures practiced by mathematics teachers during a LS strategy; (2) to determine the nature of the topics and mathematics content domains used by mathematics teachers to carry out LS; (3) to know the frequency at which LS practice is carried out; and (4) to identify the views of teachers on the impact of LS on their professional development.

2.1. Sample. The questionnaire was submitted to a sample of 149 of Saudi Arabian mathematics teachers working at the primary public schools that participated in the LS strategy who were selected by using the purposive sampling method; all of the participants are male: 73 of them with more than 10 years' experience, 48 between 6 and 10 years, and 28 between 1 and 5 years of experience. The researcher accessed sample through the Administration of Education in Riyadh, where the implementation of the lesson study strategy is still in beginning and not mandatory; it was applied in a number of primary schools in Riyadh, while it was not applied in other schools. 


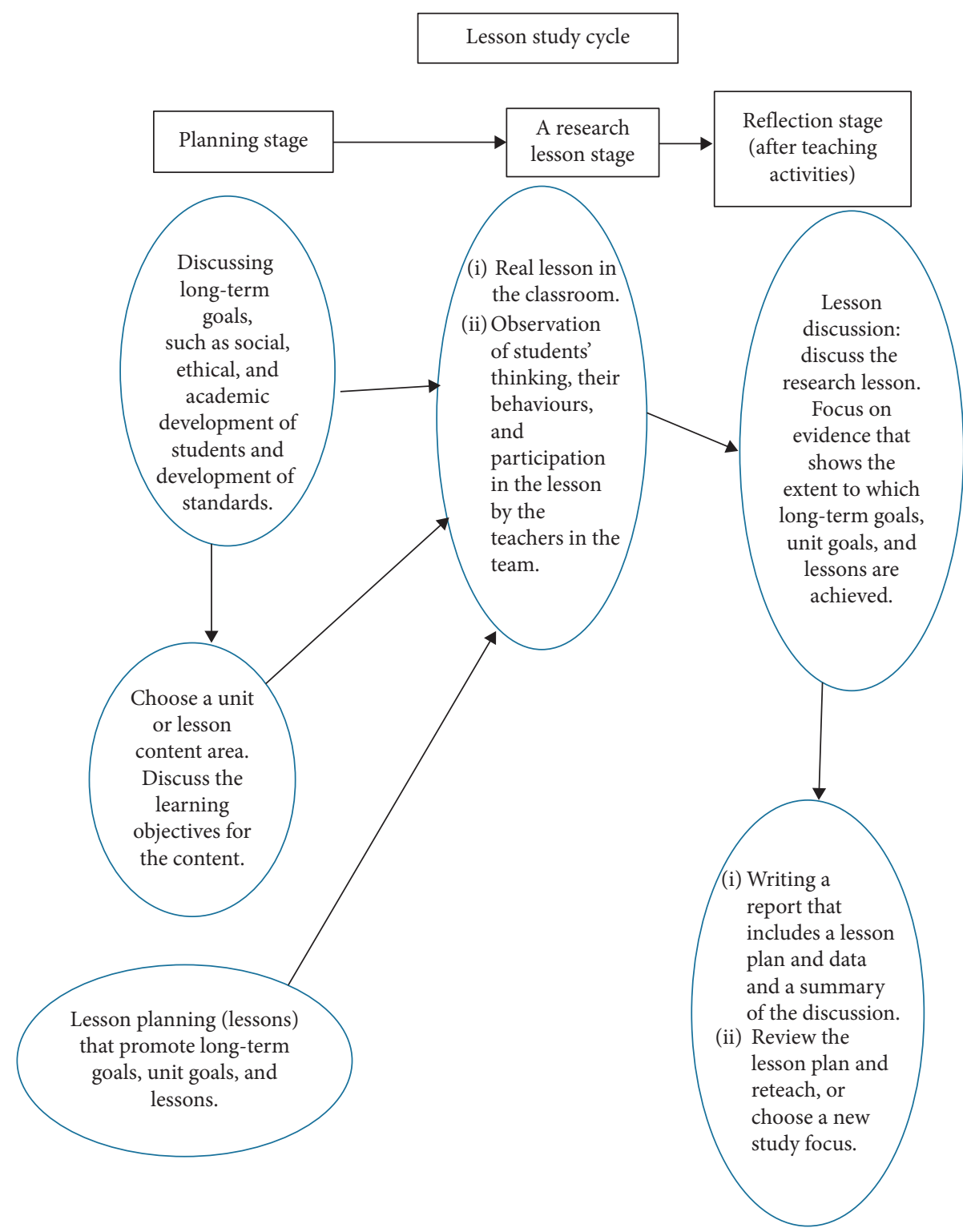

Figure 1: The stages of the lesson study.

2.2. Data Sources. In this study, the researcher used a teacher questionnaire, which included closed items covering the following five themes: LS activities and procedures (15 items, yes/no responses), topics used by teachers for practicing LS (3 items, respondents could select more than one response), mathematics content domains used when practicing LS (3 items, respondents could select more than one response), frequency at which LS was practiced (7 items, respondents could select one response), and teachers' views about the impact of LS on their professional development (18 items, rated on a 5-point Likert scale, ranging from "very high" to "very low").

To determine the extent of the impact of LS, a 5-point Likert scale was used: "very high" (5), "high" (4), "medium" (3), "low" (2), and "very low" (1). To interpret the results, the length of the category was calculated using the following equation: length of the category (range) $=5-1 / 5=0.80$. Thus, the length of the scale points was as follows: very high$=5-4.2 ; \quad$ high $=<4.2-3.40 ; \quad$ medium $=<3.40-2.60$; low $=<2.60-1.80$; and very low $=<1.80-1$.

In short, quantitative data were collected using the teacher questionnaire, while qualitative data were collected from the interview.

2.3. Questionnaire Preparation. The questionnaire was prepared according to the following procedure:

(1) Determining the objectives of the questionnaire: the questionnaire aimed to identify the activities and procedures carried out by teachers in LS and teachers' views about the impact of the implementation of LS on their professional development.

(2) Surveying several previous studies that addressed LS [28-30]. 
(3) Identifying the different parts of the questionnaire: two main parts were identified considering the literature review and the research practices in the field of education (determined by an examination of available evidence and training programs), as well as through discussions with several officials and supervisors of the LS program from the Ministry of Education and the General Administration of Education in Riyadh, and with teachers themselves. The first part included four themes-LS activities and procedures, topics used by teachers while practicing LS, mathematics content domains used for practicing LS, and frequency at which LS is practiced. The second part addressed teachers' views about the impact of LS on their professional development-several statements were formulated to determine the extent to which LS contributed to mathematics teachers' professional development.

2.4. Validation of the Questionnaire. After developing the initial version of the questionnaire, it was given to ten experts in mathematics teaching and professional development programs. Considering their comments and suggestions on the questionnaire, some statements were modified, and the final version of the questionnaire was developed.

2.5. Reliability of the Questionnaire. To calculate the questionnaire's reliability, it was administered to a sample other than the actual sample. Cronbach's alpha coefficients were calculated for each dimension of the questionnaire: activities and procedures $(0.88)$, topics $(0.76)$, mathematics content domains (0.85), frequency of practice (0.81), and teachers' perspectives (0.69).

2.6. The Interview. After administering the quantitative questionnaire, a qualitative unstructured interview was conducted with a sample of fifteen teachers, used to obtain in-depth explanations of some of the findings that emerged from the questionnaire. The interview comprised openended questions; participants could freely express their opinions and reflect on their experiences [31, 32]. Some examples of the questions are as follows: "How were you able to carry out the activities included in Table 1?" "Do you think that the practice of LS for difficult topics helps facilitate the explanation of those topics and thus results in better understanding among students?" "Do you think that some domains of mathematics are more appropriate for LS?" "What factors affected the frequency of your practice or participation in LS?" "To what extent do you think the training program influenced your professional development?" The data obtained from the interview were analysed using open and closed coding; Saldaña [33] described a code as "a word or short phrase that symbolically assigns a summative, salient, essence-capturing, and/or evocative attribute for a portion of language-based or visual data". The coding was performed by the present researcher and another expert. About $89 \%$ agreement was reached between the two coders.

\section{Results and Discussion}

This section includes a discussion of the five research questions or study objectives mentioned above. Interviewees' answers are included within the discussion of the questionnaire results.

3.1. LS Activities and Procedures. Table 1 shows the results of the first research question related to LS activities and procedures. The results indicated that the teachers participated in most LS activities, but more than $30 \%$ of teachers did not participate in the activities included in items $7,12,13$, and 14. This may indicate that they did not have enough time to perform those activities, possibly due to the rigid time allocated for mathematics in most educational systems including Saudi Arabian. According to the result for item 14, this could also be due to weak collaboration between the educational departments at universities and the practitioners at schools. The result related to item 12 indicates that there are some teachers who neglected reteaching during the lesson study activities in another class by another teacher. This may mean that the lesson study strategy is not applied in the right way. Having missing this critical step may prevent the discovery of more information about teaching and student learning that help teachers for development of teaching skills and improvement of student learning. On the other hand, the teachers were found to be interested in some activities; for example, the item 2 is the highest percentage and may indicate that teachers have awareness about defining the long-term goals of the LS cycle, which consider an important step that teachers can base on to address and solve many problems that encounters students while learning mathematic. To obtain teachers' perspective regarding the practice of LS activities, interviewees were asked the following: "How were you able to carry out the activities included in Table 1?" They indicated that they had to postpone some of their lessons to participate in LS activities. Interviewees' answers support the results shown in Table 1, which indicate that most teachers participated in all activities. Stigler and Hiebert [7] identified the following eight steps of LS: "(1) defining and researching a problem, (2) planning the lesson, (3) teaching and observing the lesson, (4) evaluating the lesson and reflecting on its effect, (5) revising the lesson, (6) teaching and observing the revised lesson, (7) evaluating and reflecting a second time, and (8) sharing the results". Most of these eight steps were included in this study (Table 1). Table 1 includes LS activities as well as some LS procedures.

3.2. Nature of the Topics Used by Teachers in LS Practice. Regarding the nature of the topics for which teachers carried out LS, the results indicate that about $43.3 \%$ of respondents chose "difficult topics", $48 \%$ chose "selected topics", while only $8.7 \%$ chose "every topic," To get more insight into these findings, interviewees were asked the following question: 
TABLE 1: Descriptive statistics for lesson study (LS) activities and procedures.

\begin{tabular}{|c|c|c|c|c|c|}
\hline \multirow{2}{*}{$\mathrm{N}$} & \multirow{2}{*}{ First theme: LS activities and procedures } & \multicolumn{2}{|c|}{ Yes } & \multicolumn{2}{|c|}{ No } \\
\hline & & $F$ & $\%$ & $F$ & $\%$ \\
\hline 1 & Participating in a discussion session and drawing $\mathrm{u}$ & 126 & 84.6 & 23 & 15.4 \\
\hline 2 & $\begin{array}{l}\text { Defining the long-term goals of the LS cycle, such as developing students' mathematical thinking, providing } \\
\text { students with problem-solving skills, increasing their achievement level, improving students' attitudes and } \\
\text { motivation to learn mathematics, and preparing students for national and international tests. }\end{array}$ & 134 & 89.9 & 15 & 10.1 \\
\hline 3 & Carefully selecting the target lesson (research lesson) by participating teachers & 129 & 86.6 & 20 & 13.4 \\
\hline 4 & Identifying the lesson objectives considering the objectives of the unit and the goal of the dis & 131 & 87.9 & 18 & 12.1 \\
\hline 5 & Each teacher proposing effective methods to teach the lesson & 131 & 87.9 & 18 & 12.1 \\
\hline 6 & Collaboratively preparing a prelimin & 119 & 79.9 & 30 & 20.1 \\
\hline 7 & Preparing the fin & 104 & 69.8 & 45 & 30.2 \\
\hline 8 & Collectiv & 112 & 75.2 & 37 & 24.8 \\
\hline 9 & Holdi & 121 & 81.2 & 28 & 18.8 \\
\hline 10 & Giving the teacher an opportunity to & 119 & 79.9 & 30 & 20.1 \\
\hline 11 & $\begin{array}{r}\text { Giving the observers an opportunity to comment constructi } \\
\text { questions to the impleme }\end{array}$ & 126 & 84.6 & 23 & 15.4 \\
\hline 12 & $\begin{array}{l}\text { Reteaching the same lesson by another teacher in a new classroom after modifying and further developing the } \\
\text { lesson plan based on the observations and the deliberative discussion session. }\end{array}$ & 96 & 64.4 & 53 & 35.6 \\
\hline 13 & A teacher assum & 101 & 67.8 & 48 & 32.2 \\
\hline 14 & $\begin{array}{l}\text { Participation of experts from universities, researchers, and education leaders in LS activi } \\
\text { identification of the distant goal of the LS cycle, observation, or discussion s }\end{array}$ & 92 & 61.7 & 57 & 38.3 \\
\hline 15 & Writing the LS report after fully completing the LS course & 120 & 80.5 & 29 & 19.5 \\
\hline
\end{tabular}

"Do you think that the practice of LS for difficult topics helps facilitate the explanation of those topics and thus results in better understanding among students?"

Interviewees' responses show that they used the LS strategy for difficult topics as it allowed them to focus on those topics by preparing good teaching plans and exchanging experiences among teachers regarding how to deal with difficulties in those topics. This must have helped them overcome those difficulties, ultimately leading to a better understanding of the topics among students, for example, of those topics operations with fractions, long division. This finding partly explains the finding that $43.3 \%$ of teachers conducted LS using difficult topics. In this regards, Burghes and Robinson [34] referred that lesson study has addressed different topics including the topics that have proved challenging for students in the past.

3.3. Mathematics Content Domains Used in LS. According to Table 2, most teachers indicated that they practiced LS in the domains of "numbers and algebra," followed by "numbers and algebra, geometry and measurement, and statistics and data," "statistics and data," and "geometry and measurement." The lowest percentage of teachers indicated that they practiced LS for teaching all mathematics content domains, which supports the result that many teachers practiced LS activities for teaching difficult topics. It was, in fact, expected that teachers would practice LS for all domains because LS is not content specific but can be implemented in teaching all topics and all mathematics content domains. To obtain more in-depth information about this issue, interviewees were asked the following: "Do you think that some domains of mathematics are more appropriate for LS?" Most noted that the LS strategy can be used for all domains of mathematics, but that the domain of numbers and algebra, especially numbers, represents a large proportion of the content of mathematics taught in primary schools. This explains the high percentage of teachers who practiced LS in numbers and algebra.

Doig and Groves [35] emphasised that all teachers must deeply engage in LS practice while planning and executing their lesson. Such engagement requires effective collaboration, regardless of the content being taught [36]. Teachers should teach collaboratively if they wish to improve their classroom teaching and practice and to thus enhance students' learning. Furthermore, teachers need to collaborate on designing lessons, observe each other's teaching as well as students' learning, and engage in responsible reflection on each other's instructional strategies $[35,36]$.

3.4. Frequency of Practicing LS Activities. According to Table $3,22.8 \%$ of teachers indicated that they practiced LS activities once per month, $20.1 \%$ indicated that they practiced it every two weeks, and $15.4 \%$ indicated that they practiced it once in the academic year. In this regard, Kusumah and Nurhasanah [37] indicated that LS should be designed and conducted as a series of long-term professional development programs, not as a single short-term program, to improve teachers' teaching strategies. However, LS requires enough time for in-depth discussion of the lesson plan, and hence, teachers in the LS team should have enough time to organise multiple meetings to plan and conduct a lesson. In this context, interviewees were asked the following: "What factors affected the frequency of your practice or participation in LS?"

Interviewees' responses indicate that repetition of their practice or participation in LS depended on the teaching load assigned to them, in addition to their other school activities, duties, and responsibilities, such as monitoring 
TABle 2: Mathematics content domains used for lesson study (LS) practice.

\begin{tabular}{|c|c|c|c|}
\hline I practiced LS for... (you can choose more than one alternative or specify a specific domain only) & Frequency & $\%$ & Rank \\
\hline Numbers and algebra & 62 & 41.6 & 1 \\
\hline Numbers and algebra, geometry and measurement, and statistics and data & 24 & 16.1 & 3 \\
\hline Statistics and data & 23 & 15.4 & 2 \\
\hline Geometry and measurement & 15 & 10.1 & 4 \\
\hline Numbers and algebra, geometry and measurement & 12 & 8.1 & 5 \\
\hline Numbers and algebra, statistics and data & 7 & 4.7 & 6 \\
\hline Geometry and measurement, statistics and data & 4 & 2.7 & 7 \\
\hline All & 2 & 1.3 & 8 \\
\hline Total & 149 & 100.0 & \\
\hline
\end{tabular}

TABLE 3: Frequency of practicing lesson study.

\begin{tabular}{lcc}
\hline I practice lesson study.... & Frequency \\
\hline Once per month & 34 & 22.8 \\
Every two weeks & 30 & 20.1 \\
Once per academic year & 23 & 15.4 \\
Twice per week & 22 & 14.8 \\
Never practice it & 18 & 12.1 \\
Once per semester & 15 & 10.1 \\
Once a week & 6 & 4.00 \\
Daily & 1 & 0.7 \\
Total & 149 & 100.0 \\
\hline
\end{tabular}

TABLE 4: Teachers' perspectives about the impact of lesson study (LS) on their professional development (PD).

\begin{tabular}{|c|c|c|c|c|c|}
\hline & Impact of LS on PD & Mean & SD & $\begin{array}{l}\text { Level of } \\
\text { impact }\end{array}$ & Rank \\
\hline 1 & LS contributed to enhancing my mathematical knowledge. & 4.517 & 1.7422 & Very high & 1 \\
\hline 2 & LS contributed to the development of my pedagogical knowledge. & 3.869 & 1.0582 & High & 7 \\
\hline 3 & LS contributed to my understanding of better ways to teach some mathematics content. & 3.859 & 1.0627 & High & 10 \\
\hline 4 & LS contributed to a better understanding of students' thinking patterns. & 3.785 & 1.0050 & High & 14 \\
\hline 5 & $\begin{array}{l}\text { LS helped me to identify and implement appropriate actions and strategies to teach concepts, } \\
\text { generalisations, and mathematical skills. }\end{array}$ & 3.899 & 1.0589 & High & 4 \\
\hline 6 & $\begin{array}{c}\text { Observing and analysing the performance of other teachers allowed me to reflect on my } \\
\text { teaching practices. }\end{array}$ & 3.946 & 1.1275 & High & 2 \\
\hline 7 & LS contributed to my classroom management skills. & 3.718 & 1.0405 & High & 18 \\
\hline 8 & LS contributed to the development of mathematical infere & 3.772 & 1.0531 & High & 16 \\
\hline 9 & $\begin{array}{c}\text { LS allowed me to understand other teachers' actions in planning, implementing, and evaluating } \\
\text { mathematics lessons. }\end{array}$ & 3.839 & 1.0889 & High & 11 \\
\hline 10 & LS contributed to increase my self-esteem and self-efficacy. & 3.899 & 1.0751 & High & 5 \\
\hline 11 & $\begin{array}{c}\text { Through LS, I gained valuable knowledge and experience, which made me feel that I am a better } \\
\text { mathematics teacher than before. }\end{array}$ & 3.886 & 1.0440 & High & 6 \\
\hline 12 & LS contributed to a deeper understanding of how students learn mathematics lessons. & 3.866 & 1.0833 & High & 8 \\
\hline 13 & LS made me more aware of students' needs. & 3.779 & .9797 & High & 15 \\
\hline 14 & LS contributed to my ability to identify the difficulties that students face in mathematics classes. & 3.859 & .9875 & High & 9 \\
\hline 15 & $\begin{array}{c}\text { LS made me capable of effectively connecting theory and practice through planning, } \\
\text { implementation, and reflection }\end{array}$ & 3.745 & 1.0004 & High & 17 \\
\hline 16 & $\begin{array}{c}\text { The feedback I received from the team contributed to my knowledge of my strengths and } \\
\text { shortcomings. }\end{array}$ & 3.819 & 1.0653 & High & 12 \\
\hline 17 & $\begin{array}{c}\text { LS made me appreciate the role of observation, discussion, and reflection in the development of } \\
\text { teaching practices. }\end{array}$ & 3.799 & 1.0597 & High & 13 \\
\hline 18 & $\begin{array}{l}\text { The LS strategy contributed to changing my convictions about the importance of sharing } \\
\text { experiences among teachers. }\end{array}$ & 3.926 & 1.0597 & High & 3 \\
\hline Total & & 3.877 & & High & \\
\hline
\end{tabular}

students. Increased teaching load and responsibilities provide teachers with fewer opportunities to participate in LS. Moreover, engaging in LS practice sometimes leads to a delay in conducting their lessons. Regarding the reason for the delay, interviewees responded that they have to conduct many classes (sessions) and carry out several duties, and 
hence, when it was decided to practice LS activities, they were forced to postpone some of their classes. Concerning this issue, Stigler and Hiebert [7] indicated that Japanese teachers prefer to spend more in LS practice because it can improve their teaching, especially in the context of classroom lessons, which can indeed lead to an improvement in students' learning, which is the final target of the learning process.

Japanese schools generally specify one afternoon a week for LS activities. However, the process of designing lesson study may take more than half a year [38] or about $10-15$ hours over a 3 - to 4 -week period $[39,40]$. The present study, therefore, suggests that schools or educational officials should specify an appropriate time every week for all mathematics teachers to conduct pre- and postdiscussion of mathematics lessons. This may lead to an improvement in LS practice, thereby enhancing overall educational practices.

\subsection{Impact of LS on Teachers' Professional Development.} As shown in Table 4, mathematics teachers agreed that most items included in the table represent a high impact on their professional development. The values of the weighted means ranged from 3.718 to 4.517 . The results indicate that teachers highly agreed about the impact of most items. In addition, teachers strongly agreed ("very high") that LS contributed to enhancing their mathematical knowledge. Interviewees' were asked the following question: "To what extent do you think you participating in the LS strategy influenced your professional development?" They responded that it had a significant impact, especially in their mathematical and pedagogical knowledge, and was reflective in their teaching depending on observation of other teachers. Their answers supported their responses to part two (research question five) of the questionnaire (Table 4). In this regard, Lewis [16] reported that Japanese teachers expect that LS should result in the improvement of individuals, schools, and the nation.

\section{Conclusion and Implications}

The results of this study show that most teachers had practiced LS activities. Teachers practiced LS once per month when teaching selective domains, such as numbers and algebra. Teachers also highly agreed about the importance of most items regarding the impact of LS on their professional development. This study reveals the advantage of specifying and allocating enough time for practicing LS on teachers' competencies and on students' quality of learning and thinking, as opposed to other teaching methods that neglect the implementation of LS. As revealed in the literature review, LS is a flexible approach which can be suitable for any educational system worldwide. It is important to adopt teaching and practice models that are suitable for educational systems and that can clearly link instructional improvement to observable characteristics of LS. However, the required key points and practices of LS for the development of teachers' skills in understanding and observing classroom practices are still unknown. Therefore, it is important to conduct studies to identify those key points, especially for rigid educational systems. In addition, there is also an urgent need to conduct research on the obstacles and influential factors in the success of LS.

This study was conducted only on primary schools and was limited to knowing the effect of teachers' participation in the lesson study groups regarding some aspects of their professional development from their point of view. Some lesson study groups were from the same school, while others came from different schools belonging to the same educational office. Also, some participated teachers in the LS groups may drop out of the group's participation due to absence from some activities in their school or due to special circumstances.

\section{Data Availability}

No data were used to support this study.

\section{Conflicts of Interest}

The author declares that he has no conflicts of interest.

\section{References}

[1] R. Meyer, "Lesson study: the effects on teachers and students in Urban Middle Schools," Unpublished doctoral dissertation, Baylor University, Waco, TX, USA, 2006.

[2] V. L. Akerson, K. Pongsanon, M. A. Park Rogers, I. Carter, and E. Galindo, "Exploring the use of lesson study to develop elementary preservice teachers' pedagogical content knowledge for teaching nature of science," International Journal of Science and Mathematics Education, vol. 15, no. 2, pp. 293312, 2017.

[3] A. N. Parks, "Messy learning: preservice teachers' lessonstudy conversations about mathematics and students," Teaching and Teacher Education, vol. 24, no. 5, pp. 1200-1216, 2008.

[4] L. Sims and D. Walsh, "Lesson study with preservice teachers: lessons from lessons," Teaching and Teacher Education, vol. 25, no. 5, pp. 724-733, 2009.

[5] A. Ni Shuilleabhain, Developing mathematics teachers" pedagogical content knowledge through lesson study, Doctor of Philosophy Ph.D., Trinity College Dublin, Dublin, Ireland, 2014a.

[6] A. Ni Shuilleabhain, "Lesson study and Project Maths: a professional development intervention for mathematics teachers engaging in a new curriculum," in 8th British Congress of Mathematics Education, S. Pope, Ed., pp. 255-262, Nottingham University, Nottingham, UK, 2014b.

[7] J. W. Stigler and J. Hiebert, The Teaching Gap: Best Ideas from the World"s Teachers for Improving in the Classroom, Free Press, New York, NY, USA, 1999.

[8] N. C. Verhoef, F. Coenders, J. M. Pieters, D. van Smaalen, and D. O. Tall, "Professional development through lesson study: teaching the derivative using GeoGebra," Professional Development in Education, vol. 41, no. 1, pp. 109-126, 2015.

[9] T. Wright, Investigating teachers' perspectives on the impact of the lesson study process on their mathematical content knowledge, pedagogical knowledge, and the potential for student achievement, Ph.D. Dissertations, University of New Orleans, New Orleans, LU, USA, https://scholarworks.uno.edu/td/906. 
[10] J. Ponte, "Lesson studies in initial mathematics teacher education," International Journal for Lesson and Learning Studies, vol. 6, no. 2, pp. 169-181, 2017.

[11] I. Bakkenes, J. D. Vermunt, and T. Wubbels, "Teacher learning in the context of educational innovation: learning activities and learning outcomes of experienced teachers," Learning and Instruction, vol. 20, no. 6, pp. 533-548, 2010.

[12] R. Bjuland and R. Mosvold, "Lesson study in teacher education: learning from a challenging case," Teaching and Teacher Education, vol. 52, pp. 83-90, 2015.

[13] W. W. Murawski and W. W. Lochner, "Observing coteaching: what to ask for, look for, and listen for," Intervention in School and Clinic, vol. 46, no. 3, pp. 174-183, 2011.

[14] D. Tepylo and J. Moss, "Examining change in teacher mathematical knowledge through lesson study," Lesson Study Research and Practice in Mathematics Education: Learning Together, pp. 55-77, Springer, Berlin, Germany, 2011.

[15] S. Chokshi and C. Fernandez, "Challenges to importing Japanese lesson study: concerns, misconceptions, and nuances," Phi Delta Kappan, vol. 85, no. 7, pp. 520-525, 2004.

[16] C. Lewis, Lesson Study: A Handbook of Teacher-Led Instructional Change, Research for Better Schools, Philadelphia, PA, USA, 2002.

[17] C. M. Roberts, The Dissertation Journey: A Practical and Comprehensive Guide to Planning, Writing, and Defending Your Dissertation, Corwin, Thousand Oaks, CA, USA, 2010.

[18] C. C. Lewis, R. R. Perry, S. Friedkin, and J. R. Roth, "Improving teaching does improve teachers," Journal of Teacher Education, vol. 63, no. 5, pp. 368-375, 2012.

[19] C. Lewis, R. Perry, and J. Hurd, "A deeper look at lesson study," Educational Leadership, vol. 61, no. 5, pp. 18-22, 2004.

[20] S. Herawati, "Final report: improvement of secondary school education," Government of Indonesia (GOI) and JICA, JICA, Tokyo, Japan, IMSTEP-JICA Project, 2003.

[21] A. Richit and J. Ponte, "Teachers" perspectives about lesson study," Acta Scientiae, vol. 19, no. 1, pp. 20-30, 2017.

[22] A. S. Suhaili, M. Shahrill, and M. Khalid, "The impact of lesson study on primary mathematics teachers" instructions in Brunei Darussalam," in Proceedings of the International Conference on Education in Mathematics, Science \& Technology, Seville, Spain, November 2014.

[23] A. Taylor, S. Anderson, K. Meyer, M. Wagner, and C. West, "Lesson study: a professional development model for mathematics reform," Rural Educ, vol. 26, no. 2, pp. 17-23, 2005.

[24] A. Leavy and M. Hourigan, "Using lesson study to support the teaching of early number concepts: examining the development of prospective teachers' specialized content knowledge," Early Childhood Education Journal, vol. 46, no. 1, pp. 47-60, 2018.

[25] H. Abdel-Al, "A program based on the lesson study to develop reflective thinking skills and self-efficacy among studentteachers at mathematics department, Faculty of Education," Journal of Mathematics Education, vol. 20, no. 10, pp. 156-189, 2017.

[26] Ministry of Education, School Based Professional Development, Ministry of Education, Riyadh, Saudi Arabia, 2018.

[27] National Center for Educational Professional Development, NCEPD, School Based Professional Development, Lesson Study, Ministry of Education, Riyadh, Saudi Arabia, 2018.

[28] E. A. Burroughs and J. L. Luebeck, "Pre-service teachers in mathematics lesson study," The Montana Mathematics Enthusiast, vol. 7, no. 2-3, pp. 391-400, 2010.

[29] M. Inprasitha, "How to transfer Lesson Study to outside Japan: a decade of Thailand experience," in Proceedings of the 12th International Congress on Mathematical Education (ICME12), Seoul, South Korea, 2012.

[30] K. Matanluk, K. Johari, and O. Matanluk, "The perception of teachers and students toward lesson study implementation at rural school of Sabah: a pilot study," Procedia-Social and Behavioral Sciences, vol. 90, no. 10, pp. 245-250, 2013.

[31] J. W. Creswell, Educational Research: Planning, Conducting, and Evaluating Quantitative and Qualitative Research, Pearson Education, Inc., Upper Saddle River, NJ, USA, 2005.

[32] J. W. Creswell, Research Design: Qualitative, Quantitative and Mixed Methods Approaches, Sage Publications Ltd., London, UK, 4th edition, 2014.

[33] J. Saldana, The Coding Manual for Qualitative Researchers, Sage Publications, Los Angeles, C, USAA, 2009.

[34] D. Burghes and D. Robinson, Lesson Study: Enhancing Mathematics Teaching and Learning, CfBT, Reading, UK, 2010.

[35] B. Doig and S. Groves, "Japanese lesson study: teacher professional development through communities of inquiry," Mathematics Teacher Education and Development, vol. 13, no. 1, pp. 77-93, 2011.

[36] A. F. Artzt, E. Armour-Thomas, and F. R. Curcio, Becoming a Reflective Mathematics Teacher, Lawrence Erlbaum Associates, New York, NY, USA, 2008.

[37] Y. S. Kusumah and F. Nurhasanah, "The endless long-term program of mathematics teacher professional development in Indonesia," in Professional Development of Mathematics Teachers, B. Kaur, O. N. Kwon, and Y. H. Leong, Eds., pp. 33-45, Springer, Singapore, 2017.

[38] T. Fujii, "Implementing Japanese lesson study in foreign countries: misconceptions Revealed," Mathematics Teacher Education \& Development, vol. 16, no. 1, pp. 2-18, 2014.

[39] C. Fernandez, "Learning from Japanese approaches to professional development," Journal of Teacher Education, vol. 53, no. 5, pp. 393-405, 2002.

[40] C. Fernandez and M. Yoshida, Lesson Study: A Japanese Approach to Improving Mathematics Teaching and Learning, Routledge, New York, NY, USA, 2012. 